\title{
Near-Death Experiences: A Critique of the Fischer and Mitchell-Yellin Physicalist Interpretation
}

\author{
Robert G. Mays, BSc, and Suzanne B. Mays, AA \\ Chapel Hill, NC
}

\begin{abstract}
In Near-Death Experiences: Understanding Visions of the Afterlife, authors John Martin Fischer and Benjamin Mitchell-Yellin (2016) argued for purely physicalist explanations of near-death experiences (NDEs) and against "supernatural" explanations involving objects and events-out-of-body experiences, heavenly realms, meeting deceased relatives- that have no physical reality. In our critique, we identify two major weaknesses to their argument: heavy reliance on ad hoc hypotheses and frequent appeal to "promissory materialism." Fischer and Mitchell-Yellin applied the term "hallucination" to NDEs because, by definition, they "do not correspond to reality." We found use of this term problematic for several reasons: that NDE perceptions are phenomenologically different from hallucinations, that NDE perceptions of the physical realm are nearly always veridical, and that labelling NDEs "hallucinations" pathologizes a normal, subjective experience, with potentially harmful psychological outcomes. Although Fischer and Mitchell-Yellin argued against a theory of NDEs that invokes only one explanatory factor, we argue for a likely common proximate cause for all NDEs and that the nonphysical "mind-entity theory," in which the nonmaterial mind separates from the physical body in an NDE, is a likely candidate theory with good explanatory power. We believe that ultimately the theory explaining NDEs will be corrected through the normal process of scientific inquiry, resulting in an expansion of current physicalist theory to include what is now considered supernatural, thus becoming an extended, transmaterial naturalist theory.
\end{abstract}

KEY WORDS: near-death experiences, physicalism, apparently nonphysical veridical perceptions (AVPs), ad hoc hypotheses

Robert G. Mays, BSc, is a retired senior software engineer, and Suzanne B. Mays, AA, is a Certified Music Practitioner (through the Music for Healing and Transition Program) who provides palliative care to hospitalized patients. They have studied near-death phenomena together for more than 35 years (http://selfconsciousmind.com). Correspondence regarding this article should be sent to Mr. Mays at 5622 Brisbane Drive, Chapel Hill, NC 27514; e-mail: mays@ieee.org. 
The predominant scientific view is a physicalist view of reality whereby all observable phenomena are believed to result from the interaction of physical matter and physical forces. In particular, all human experiences are presumed to be produced solely by physical interactions in the brain and body.

The book by John Martin Fischer and Benjamin Mitchell-Yellin, Near-Death Experiences: Understanding Visions of the Afterlife (2016), was based on the authors' work on The Immortality Project, sponsored by The John Templeton Foundation (p. viii, dust jacket). The book is a very well-crafted presentation of the arguments for purely physicalist explanations of near-death experiences (NDEs) and against what they called "supernatural" explanations. In a supernaturalist explanation, NDEs demonstrate (a) that there is a supernatural, heavenly realm separate from the physical world, and/or (b) that the mind is nonphysical and experiences are not solely produced by the brain and body (pp. 7-8).

In this article, we examine critically a number of points that Fischer and Mitchell-Yellin raised about NDEs and "supernaturalist" NDE theories, and we offer nonphysicalist perspectives and counterarguments. In this way, we elaborate on and add to points that Dan Punzak (2016) made in his review of this book that appeared previously in this Journal. In their treatment of NDE theories, Fischer and MitchellYellin seemed sincere; they expressed deep respect for near-death experiencers (NDErs) and the hope that their treatment displayed that respect (p. viii). In our view, the authors' arguments have a number of flaws that led them to conclusions that actually can be harmful to NDErs. We will elaborate on these points below.

In this article, we will refer to the book, The Self Does Not Die by Titus Rivas, Anny Dirven, and Rudolf Smit (2016), which we consider an excellent compendium of verified paranormal phenomena that were reported in association with NDEs. We notate these references below as $S D N D$ with specific pages, cases, or chapters. Because this book was available only in a 2013 Dutch edition until the English translation was published a few weeks after the Fischer and MitchellYellin book appeared, Fischer and Mitchell-Yellin cannot be expected to have included it in their deliberations; we admittedly refer to it ex post facto their book because it contains material critical to our arguments. 


\section{Explaining NDEs With Ad Hoc Hypotheses}

Fischer and Mitchell-Yellin referred to several famous NDEs. Initially, they focused on the cases of Pam Reynolds (SDND, case 3.29 and Chap. 11) and the man with the dentures (SDND, case 3.7 and Chap. 11). Later in the book, they developed explanations for aspects of Colton Burpo's NDE (Burpo, 2010; SDND, case 5.2) and Eben Alexander's NDE (Alexander, 2012; SDND, Chap. 11).

Fischer and Mitchell-Yellin selected aspects from each of these cases to demonstrate that a physicalist explanation is possible, or at least conceivable, for some aspect or feature of the NDE that is commonly used to justify the supernaturalist explanation. For example, Pam Reynolds underwent surgery for a brain aneurysm with induced hypothermic cardiac arrest. During the surgery, she experienced an NDE and later accurately recalled overhearing a conversation about her vein size that took place during the operation. Fischer and MitchellYellin claimed that her accurate memory was possible not because she was out of her body observing the operation, as she reported, but because the conversation registered somewhere in her brain during the surgical anesthesia and was brought to conscious awareness some time after she awoke from the surgery. Furthermore, they asserted the possibility that she did not report the loud clicks that had blasted her ears during the surgery because the clicks for some reason did not similarly come back to conscious awareness as did the comparatively quiet conversation (p. 21).

The man with the dentures suffered cardiac arrest and was transported to the hospital where he arrived unconscious. Following his resuscitation and return to consciousness, he recognized a male nurse who was walking by and reported his recollection that prior to commencement of the cardiopulmonary resuscitation process (CPR), the male nurse removed his dentures and placed them on the pullout shelf of a cart. According to Fischer and Mitchell-Yellin, however, the man's accurate memory was not the recall of an actual experience of being out of his body, as he reported. Rather, after his recovery he subconsciously constructed a visual experience from nonvisual sources, such as feeling the dentures being removed and hearing the shelf being pulled out, while he was comatose prior to CPR. He could also have subconsciously incorporated visual sources, such as the face of the nurse, which he saw after his recovery (pp. 19-20, 86). Even if the man's brain function could not support conscious awareness at the time the dentures were removed, the brain may still have been func- 
tioning to some degree, making it possible to record information that could later be recalled as a remembered conscious experience (p. 31).

In a number of NDEs, for example those of Reynolds, Alexander, and Burpo, the NDEr reported having been met by deceased loved ones in an otherworldly realm. In Fischer and Mitchell-Yellin's view, instead of being actual encounters with deceased persons and, therefore, evidence for the existence of the afterlife, these recollections are the result of the fear of dying, which is common for most people. This idea has been formalized in "terror management theory." Proponents of this theory hold that visions of deceased relatives-and even of apparent strangers -in an NDE would provide great comfort in the face of death and reassurance that one will be reunited with and welcomed by one's lost loved ones and others. In the authors' view, these experiences are actually false memories or confabulations, with embellishments that are added in telling and retelling the story, to make the narrative more coherent (pp. 66-71).

From Fischer and Mitchell-Yellin's perspective, Colton Burpo's recollections of various aspects of heaven during his NDE-such as the throne of God, sitting in Jesus's lap, and seeing wounds on Jesus's hands ("markers") - were not memories of an actual experience in heaven, as he reported. Rather, they were confabulations pieced together unconsciously by Colton from Christian picture books his parents had read to him and conversations he overheard from his father who was a minister. These false memories were encouraged by the attention his parents and others gave to him, and the memories probably became embellished through repeated requests to retell them.

Fischer and Mitchell-Yellin continued that Colton's memory of his out-of-body experience in the hospital, during which he reported he saw his mother praying and talking on the phone and his father praying by himself in another room, was not an actual memory. Rather, it was another confabulation based on what Colton would expect his parents to be doing during his surgery and what he would construct psychologically as a coping reaction to his own anxiety over his illness and surgery. Even Colton's reports of meeting and speaking with his father's grandfather and meeting his sister who died in their Mommy's tummy were more likely confabulations unconsciously constructed from actual memories, combined with inadvertent suggestions from others and embellished through enhanced attention from adults and requests to retell the experiences (pp. 134-146).

To us, Fischer and Mitchell-Yellin's analysis of these selected NDEs appears superficial. They focused only on selected NDE features. How- 
ever, even from the features they chose to highlight, a number of explanatory themes are apparent.

First, they speculated physiological processes-for example, the recording of sounds in the brain during anesthesia-that can later be selectively brought back to consciousness, thereby fitting Reynolds's NDE. Another example is the ability to subconsciously construct accurate, detailed visual experiences from nonvisual sources recorded in the brain during cardiac arrest, before CPR had started, thereby fitting the dentures case. These speculations have not been demonstrated or even suggested by the current level of neuroscientific and medical knowledge, but Fischer and Mitchell-Yellin assured readers that:

Our scientific understanding will continue to improve. We should not take our current lack of understanding regarding a particular phenomenon to be the cause of despair about the possibility of arriving at an adequate explanation of it in the future. (p. 66)

Second, they hypothesized processes driven by the near-universal fear of dying, as proposed by terror management theory, that cause NDErs to imagine meeting deceased loved ones in order to receive great comfort and reassurance in the face of death, thereby fitting all NDErs who report meeting deceased loved ones in their NDEs. This hypothesis should also apply to NDErs who claim to have completely lost their fear of death and actually desire to return to their "true heavenly home." Still, these NDErs meet deceased loved ones in a subsequent NDE. In these cases, we expect that the authors would propose a corollary for such NDErs: If NDErs claim that they have lost the fear of dying, actually, they still subconsciously fear death, or perhaps, seeing their deceased loved ones in a later NDE brings comfort and reassurance for other psychological reasons. The corollary thereby fits even these NDE cases.

Finally, the authors seemed to use a catchall hypothesis for a number of elements of an NDE, namely, imagination and confabulations pieced together unconsciously by the NDEr after the NDE. They speculated that the information may have come from prior life experience, from circumstances surrounding the brush with death, from hallucinations caused by drugs administered during the event or during the recovery, and from information inadvertently provided by others after the NDE. The NDEr's narrative may then have been further embellished by additional information inadvertently provided by listeners during a retelling. This hypothesis should apply to all aspects of the 
NDE narrative that have supernatural elements and to those NDEs in which information is obtained by apparently nonphysical means. Thus, this hypothesis fits all of the NDEs that the authors analyzed.

\section{Reliance on Ad Hoc Hypotheses}

A central problem with Fischer and Mitchell-Yellin's physicalist theory is that it relies heavily on ad hoc hypotheses, that is, hypotheses that are introduced to compensate for aspects of NDEs that do not readily fit the physicalist paradigm. Individually, each ad hoc hypothesis appears reasonable, if at times speculative. However, taken as a whole, the theory with its additional ad hoc hypotheses becomes untenable and improbable.

In their book, Fischer and Mitchell-Yellin presented four NDEs and managed to explain them fairly successfully by applying three ad hoc hypotheses and one corollary. We propose to apply the authors' theory and hypotheses to four additional NDEs that are documented in The Self Does Not Die. These are cases of veridical perception, that is, accurate perceptions during NDEs that were later verified by a third party. We will apply the three questions the authors proposed in order to analyze NDEs: (a) explain how the NDEr acquired the information in the NDE, (b) explain why this particular content would be included in an NDE, and (c) explain when the experience took place (p. 122).

The first two cases deal with purely visual perceptions of unusual objects that were out of the line of physical sight of anyone in the room. In the first case ( $S D N D$, case 2.5), a neurological patient was in a coma for several weeks, during which she had a cardiac arrest from which, after several resuscitation attempts, the team succeeded in resuscitating her. When the patient came out of her coma, she claimed to have had an out-of-body experience (OBE). She also had the obsessive habit of trying to memorize every number she came across. The patient claimed that during her OBE she had memorized the 12-digit serial number located on top of the respirator, which was about six feet in height. Nurse Norma Bowe and her colleagues wrote down the number she recited. When the respirator was taken out of the room and needed to be dusted, a custodial staff member climbed up a ladder and read out exactly the same number as the patient had recited.

In the second case (SDND, case 2.6), physician John Lerma described how an elderly patient, Ricardo, was resuscitated from two cardiac arrests. Ricardo later described that during his NDE he had floated up in the trauma room and had spotted a 1985-quarter lying 
on the right-hand corner of the 8 -foot-high cardiac monitor, amidst the dust. Lerma climbed a ladder in the presence of nurses and found the quarter just as Ricardo had described it, including the date.

A question in these two cases is how the patients acquired the information. In both instances, the patient could have climbed up and seen the object. Or Ricardo could have placed the quarter there himself. Both of these ad hoc hypotheses are conceivable but not very likely, given the patients' physical conditions at the time. A favorite hypothesis among skeptics is that the patients overheard a conversation among the hospital staff about the objects and incorporated the information unconsciously in their narrative. This ad hoc explanation seems very improbable, especially regarding the 12 -digit serial number of a respirator.

Another question is why this particular content would be included in these NDEs. Bowe's patient had an obsession with numbers, so perhaps Ricardo had obsession with coins. This is a possible ad hoc explanation in both cases but does not explain how the information could be so precise. Another favorite hypothesis among skeptics- that it was a lucky guess - might explain the coin-its precise location, denomination, and date-but probably not explain the serial number. Another favorite $a d$ hoc explanation is that the entire story is a fabrication of the person reporting it. Again, this explanation might apply in some NDE reports but not all of them.

A third question is when the experience of apparent veridical perception actually occurred. Depending on the ad hoc hypotheses that were selected from the previous two questions, the perceptions might have been imagined and incorporated in the NDErs' accounts after the medical event.

In the last two cases, the NDE included the veridical perception of unusual, purely visual events in the hospital that were out of the line of physical sight. These unusual events occurred at specific times during their surgeries and thus have specific "time anchors." In another case (SDND, case 1.5), Al Sullivan had emergency cardiac surgery, during which his eyes were taped shut and a surgical drape over his head blocked any possible physical perception of the surgeon, Dr. Takata. During the surgery, Sullivan experienced an OBE and floated above his body, looking down. He noticed that Takata seemed to be "flapping" his arms as if to fly. After he had recovered, Sullivan told his cardiologist, Dr. LaSala, of this unusual behavior. Takata had the habit of placing his hands on his chest to avoid contaminating them and pointing with his elbows when he needed to direct his surgical 
assistants. Both LaSala and Takata could not explain how Sullivan could have known of this behavior, with Sullivan being under anesthesia and with physical eyesight blocked and the behavior involving no sound or touch - perceivable only through a "visual" process.

In the fourth case we will consider (SDND, case 3.1), anesthetist Jean-Jacques Charbonier recounted that he operated on a woman under general anesthesia. As soon as she awoke, the patient described to Charbonier her operation as if she had been near the ceiling; she also described the operation that took place in the next theater: the amputation of a leg. The patient saw that the surgical personnel put the leg in a yellow plastic bag. Charbonier checked afterwards: The operation had indeed taken place in the next theater, and a leg had been amputated at the same time his patient had been under anesthesia. The procedure for disposal of the leg had used a yellow plastic bag.

A question with regard to these last two cases is how the patients acquired the information. Again, proponents of a favorite ad hoc hypothesis would assert that Sullivan overheard a conversation among the hospital staff about Takata's strange behavior during surgery, or he was told directly about it, and he consciously forgot having heard the information but unconsciously incorporated it in his narrative as if he had actually seen it. This explanation is certainly possible and could be checked-but it does not work for the second case. Charbonier's patient described the leg amputation as soon as she woke up. Here another favorite, somewhat speculative ad hoc hypothesis of skeptics could apply: Certain brain waves from the surgical team in the next theater could have been transmitted through the wall to the patient during anesthesia. Although anesthesia induces ordinary unconsciousness, these brain waves could still make an impression on the patient's brain, which later could be incorporated in the patient's narrative, even as soon as she woke up. Of course, such a hypothetical process is not supported by any current neuroscientific knowledge, but it is certainly conceivable that such a mechanism will be found as scientific understanding continues to improve.

Another question is why, in the last two cases, particular contentsurgeon's flapping arms; amputation in adjacent operating roomwould be included in the NDEs. One speculation would be that surgical patients are typically anxious about their physical condition and want to establish rapport and trust with their physician. Therefore, they would be inclined to disclose what they imagined they experienced during surgery, in order to be reassured and to establish rapport.

A final question regarding these cases is when the experience of 
apparent veridical perception actually occurred. The explanations for both cases depend on ad hoc hypotheses that the information was not perceived directly but was "transmitted" in some way and then incorporated in the NDErs' accounts after the medical event.

Consideration of these four NDE cases shows that further ad hoc hypotheses must be invoked to explain NDEs from the physicalist position. With these four additional cases, we count nine additional ad hoc hypotheses that potentially could be invoked.

These four cases, plus the cases of Reynolds and the dentures man, are six of the 68 cases of NDE veridical perceptions presented in The Self Does Not Die. Many of the additional cases are similar to the four that we cited here, for example, the red shoe on the hospital roof ( $S D N D$, case 2.11), Maria's tennis shoe (SDND, case 2.3), the smoking grannies ( $S D N D$, case 2.14), Tom Aufderheide's patient (SDND, case 3.13 ), and Lloyd Rudy's patient (SDND, case 3.11). However, twists to many of these narratives require further ad hoc hypotheses to the physicalist theory. Moreover, once some of these hypotheses are tested against the facts of particular NDE cases, they may prove not to apply to those cases, so further hypotheses will need to be invoked.

A theory that must continually rely on additional ad hoc hypotheses - even a theory as firmly established as physicalism - at some point becomes untenable and improbable. We believe the collective weight of evidence of veridical perception cases has not only reached but substantially passed this tipping point.

\section{Hyperreal Experiences in NDEs: Reality or Hallucinations?}

NDErs commonly report their experiences as being "hyperreal," that is, more real than the experience of physical reality. Their experience is hyperreal not only in the transmaterial aspects of the NDE-the beautiful heavenly realms and encounters with spiritual beings-but also their experience of material reality itself whereby perceptions are clearer and more lucid than during ordinary waking consciousness. Fischer and Mitchell-Yellin acknowledged that NDEs are experienced as real, but they continued:

We shall use the term "accurate" throughout the remainder of the book to mean "truthful" or "corresponding to external reality." An $a c$ curate experience depicts reality as it really is. Not all real experiences are accurate. Hallucinations, illusions, dreams, delusions-these may 
all be real experiences. People really do have them. But they are not accurate experiences. They do not correspond to reality. (p. 35)

Fischer and Mitchell-Yellin gave no formal definition of "reality," but one can infer from their usage that they are referring to the consensus physical sensory data of one's waking phenomenal experience. Yes, in this sense, hallucinations, illusions, dreams, and delusions are not "real," but NDEs differ from these four phenomena in at least two ways: Whereas people returning to normal waking consciousness typically look back upon these four phenomena as unreal, people returning to normal waking consciousness typically look back upon their NDEs to be as real or more real than waking conscious reality; and whereas the vast majority of percepts of these four phenomena do not correspond to consensus reality, many percepts of NDEs are accurate and $d o$ correspond to consensus physical reality. In addition to the NDE cases of verified veridical perceptions we cited above, nearly 100 more cases of verified paranormal phenomena associated with NDEs are presented in The Self Does Not Die. These cases include accurate information conveyed telepathically, accurate information about deceased persons unknown to the NDEr, accurate information about deceased persons not known to have died, objective observation of the NDEr by others during the NDE, paranormal healings following the NDE, and paranormal abilities following the NDE. Undoubtedly, further ad hoc hypotheses can be invoked to explain all of these cases in physicalist terms. Nevertheless, it is not correct to describe all aspects of NDEs as inaccurate and "not corresponding to reality."

\section{Differences Between NDEs and Hallucinations}

Fischer and Mitchell-Yellin applied the term "hallucination" to NDErs' perceptions because, by the authors' definition, these perceptions are unreal, that is, "they do not correspond to reality" (p. 35). The use of a term categorically in this way may be quite acceptable in philosophical discourse, but it is more prudent in scientific inquiry to let the phenomena dictate the relevant distinctions.

In particular, the experiences in NDEs have been contrasted with hallucinations that are attributed to other causes, such as sedatives, painkilling drugs, sleep deprivation, psychedelics, and confusional states. Researchers Kenneth Ring (1980, pp. 83, 210), Michael Sabom (1982, pp. 168-171), Penny Sartori (2008, pp. 275-276), and Janice Holden (2009, pp. 201-202) have all found that the experiences reported in NDEs are quite different from hallucinations. 
First, Sartori (2008) found that hallucinations occurring in a hospital setting had many illusory components that could be traced to background noises, staff or family conversations, or tactile stimulation during sedation or when sedation was discontinued. In contrast, the perceptions of the physical realm in NDEs were very accurate. Holden (2009, pp. 193-199) summarized an analysis of cases of apparently nonphysical veridical perceptions during the material aspectobserving the material environment—of NDEs that had been reported in the NDE research literature, in which the veridical elements were reported to be corroborated. Of 93 cases, she found 86 cases (92\%) were completely accurate, 6 cases (7\%) had some error, and 1 case (1\%) was completely erroneous. More importantly, of the 86 cases that were completely accurate, 13 cases were verified by the experiencer only, 38 were verified by others per the report of the experiencer, and 35 were verified by objective (third-party) sources. These last 35 cases were all included in the compilation in The Self Does Not Die, plus another 33 cases that were reported later.

Thus, one can conclude that nearly all perceptions of the physical realm in an NDE are accurate or, as Fischer and Mitchell-Yellin would probably prefer, from the physicalist perspective, they are very accurate confabulations combined with some very lucky guesses. Either way, perceptions of the physical realm in an NDE are accurate; they correspond to reality; they are real. If the reported perceptions were in fact confabulations, one would expect at least as many erroneous as accurate memories to be reported, and if the perceptions were in fact guesses, there should be hundreds more cases reported involving complete error. Neither result is the case according to Holden's (2009) analysis. Furthermore, it is highly unlikely that so many erroneous cases would have gone intentionally or unintentionally unreported by researchers, the vast majority of whom we believe to be both careful and ethical.

Second, researchers Ring, Sabom, and Sartori found that the reported hallucinations had no common theme; were highly variable and idiosyncratic, disjointed, and irrational, often with some elements of paranoia; and were devoid of real-world relevance to the person. In contrast, the NDE narratives were coherent, contained common themes and common elements, and included information personally relevant to the NDErs.

Third, researchers Sabom, Sartori, and Holden compared people who have experienced both hallucinations and an NDE. These patients reported that the two experiences have distinctly different qualities, 
in four ways: (a) Their hallucination felt unreal or dream-like, whereas they were emphatic that their NDEs were definitely real; (b) In their hallucinations, their experiences had the quality of being a spectator, whereas in their NDEs, they experienced and participated in events, which actually happened to them; their essential self was involved; (c) As stated previously, with their hallucination, they recognized later that the experiences were not real, that they had been hallucinating; or they thought the experiences were authentic at the time, but later became aware the experiences were not factual; whereas in their NDEs, the experiences remained real to them; and (d) The memories of their hallucinations were less vivid and tended to fade, whereas the memories of their NDEs remained as vivid and real as when they had just experienced their NDEs, even if decades had passed. Readers interested in a first-hand account are referred to Alexander (2012, p. 115-119) provided an excellent contrast between the delirium, hallucinations, delusions, and paranoia of his post-NDE "ICU psychosis," a common syndrome among patients admitted to critical care settings, and the "astonishing clarity and vibrant richness-the ultra-reality" (p. 117) of the heavenly realms of his NDE.

\section{Differences Between NDE Memories and Real or Imagined Memories}

The last point - that memories of an NDE are vivid and indelible and persist as memories of real events - has been supported by several studies that compared memories of the NDE with real and imagined memories-and to our knowledge has not been refuted in any published study. The physicalist view holds that NDE memories, especially of the transmaterial aspects of the experience-the heavenly realms, spiritual beings, and deceased relatives-are unreal, imaginary events that the brain imagines or fabricates from subliminally perceived impressions just before, immediately after, or even during the period of unconsciousness. Indeed, the physicalist considers the transmaterial events experienced in an NDE to be unreal because they presumably do not correspond to physical reality.

However, four recent studies conducted in Europe and the United States-conducted by Thonnard, Charland-Verville, Brédart, Dehon, Ledoux, Laureys, and Vanhaudenhuyse (2013); Palmieri et al. (2014); Moore and Greyson (2017); and Martial, Charland-Verville, Cassol, Didone, Van Der Linden, and Laureys (2017) —all showed that such explanations do not fit the actual characteristics of NDE memories. 
These studies compared the characteristics of memories of NDEs with memories of real and imagined events from others who had not had an NDE. In particular, the NDE memories had significantly more characteristics, such as visual details, memory clarity, self-referential information-being involved in the event, and emotional content, as compared with memories of imagined and even real events.

In their study, Thonnard et al. (2013) of the University of Liège in Belgium concluded that NDEs cannot be considered as imagined events, which have significantly fewer characteristics. The events in NDEs are more accurately understood as events that NDErs actually perceived and in which the NDErs remember having been actively involved. Moore and Greyson (2017) found that "memories of NDEs are more vivid and detailed than memories of other real events from the same time period" (p. 123). Further analysis of memory characteristics by Martial et al. (2017) showed that a greater number of memory characteristics were associated with higher NDE Scale scores-a measure of the "intensity" or "depth" of the NDE-but not with greater recency of the NDE. These results indicate that NDE memories are more vivid and complex for "deeper" NDEs_-having more elements that are more intensely experienced, but regardless of NDE depth, NDE memories do not fade over time.

The comparison of NDE memories showing more characteristics than real and imagined memories is hard to reconcile with the physicalist view that the experiences in an NDE are imagined events or are fabricated from subconsciously perceived impressions or confabulated with information from other sources. Fischer and Mitchell-Yellin might propose another ad hoc hypothesis that the vivid, indelible memories of the heavenly realms and spiritual beings are an important emotional coping mechanism to achieve reassurance after surviving a close brush with death.

\section{The Pre/Trans Fallacy}

If the transmaterial aspects of NDEs truly are hallucinations, that is, experiences of events, beings, places and objects that are truly unreal, then there are two different kinds of hallucinatory experiences, even from the physicalist viewpoint. First, there are "ordinary hallucinations" associated with "ordinary" causes such as sedatives, painkilling drugs, sleep deprivation, psychedelics, confusional states, and psychoses. Then there are "transmaterial hallucinations" associated with NDEs and perhaps other experiences, such as mystical experi- 
ences, peak experiences, accurate precognitive dreams, and accurate knowledge of future events—-such as the $9 / 11$ attacks.

The question arises how a rational person knows whether or not transmaterial experiences are real. One approach would be to consider unreal any experiences that are not part of everyone's, or even most people's, experience. However, if a substantial percentage of people have transmaterial experiences, such as NDEs and similar extraordinary experiences, and the experiences are reasonably consistent among these people, the transmaterial experiences could represent another aspect of reality, one that is "transpersonal."

Proponents of an entire subfield of psychology-transpersonal psychology-recognize transcendent aspects of human experience that have at least subjective validity and meaning to human beings. People who have not had direct experience with transcendent states of consciousness typically have difficulty relating to such experiences. As philosopher Ken Wilber (2000, p. 211) expressed it, those inexperienced with transcendent states are prone to the "pre/trans fallacy," that is, considering trans-rational states, such as those involved in NDEs, as pre-rational states, such as superstitious beliefs, dreams, false memories, drug-induced hallucinations, and psychoses. On the basis of this distinction, we propose that Fischer and Mitchell-Yellin could revise their perspective on NDEs, without abandoning their physicalist stance, to acknowledge at least that there are different kinds of "hallucinatory" experiences - that the transmaterial experiences in NDEs are not the same as ordinary, pathological hallucinations.

In 1994, the American Psychiatric Association revised its Diagnostic and Statistical Manual of Mental Disorders (DSM-IV) to include a new, nonpathological category (a "V code") for "Religious or Spiritual Problems." Chad Johnson and Harris Friedman (2008) pointed out that this category can help clinicians to differentiate "nonpsychopathological religious/spiritual/transpersonal (R/S/T) experiences from those that might evidence psychopathology" (p. 506). The recognition that there are valid, nonpathological transpersonal experiences in normal human experience would be welcome in discourse about NDEs.

\section{"Hallucination" Implies Mental Pathology}

The distinction between NDE transmaterial experiences and ordinary, pathological hallucinations can clarify the authors' treatment of the case of an NDE that occurred during an LSD trip (pp. 161-162). 
Fischer and Mitchell-Yellin quoted an account from Oliver Sacks's book Hallucinations (2012, pp. 101-102) of an LSD trip Eric S. had with a friend in the late 1970s. This particular trip was different from Eric's earlier acid trips and included apparently veridical telepathic communication with his friend. However, there were still some disjointed, non-veridical elements, such as seeing a video replay of events in his urine stream and seeing puffs of gas shooting out of his skin cells in perfect smoke rings. Then the narrative changed: "I left my body and hovered in the room above the whole scene, then found myself traveling through a tunnel of beautiful light into space and was filled with a feeling of total love and acceptance" (p. 161). Eric's experience at this point was a classic NDE, including a life review and an encounter with a voice who told him that humans are "Love and Light." We would expect that he would describe this part of his trip as very real and that his perceptions of his physical surroundings during the OBE portion of the experience were completely veridical. He said that his memory of this experience "will live with me forever."

Fischer and Mitchell-Yellin seemed to make the point that this very meaningful NDE was induced by LSD, that Eric knew it was, and that these conditions rendered the experience significant for Eric but ultimately hallucinatory and, thus, invalid as a genuine spiritual experience (p. 169). If that is the authors' implication, it is incorrect because psychedelics induce both ordinary, unreal hallucinations and the normal transmaterial experiences in NDEs of the coherent, meaningful, nonpathological religious/spiritual/transpersonal type, which despite being "hallucinatory," nevertheless include veridical (real) perceptions of physical reality. The second half of Eric's LSD trip matches a typical NDE because it was an NDE.

A recent study led by Vanessa Charland-Verville and Steven Laureys (2014) of the University of Liège compared NDE reports resulting from life-threatening events leading to coma to "NDE-like experiences" occurring after non-life-threatening events such as during sleep, fainting, meditation, drug or alcohol use, or other non-life-threatening situations. The subjects' NDE scale score indicated the level of intensity of the experience and the number of features or elements indicated the richness of the NDE content. Surprisingly, the results showed no significant difference in either the intensity or content of the NDE between the two groups. This finding means that NDEs occurring at either end of the closeness-to-death spectrum cannot be distinguished: They are the same experience, whether they occurred in the context of a cardiac arrest, surgery, psychedelic drugs, meditation, or sleep. In 
particular, it is well known in NDE literature that psychedelics sometimes appear to facilitate NDEs (for example, Kolp, Young, Friedman, Krupitsky, Jansen, \& O'Connor, 2007; Liester, 2013).

NDEs are not pathological but, rather, are normal experiences. According to the DSM-IV and later editions, an NDE is not a psychiatric symptom, nor an indication of psychosis or other mental illness, nor a stigma. Bruce Greyson (2014) compared "spiritually transformative experiences" (STEs), which include NDEs, to psychotic experiences. Drawing on his own clinical experience and research data and the work of a number of others, Greyson (2014) showed that psychoses and STEs in general differ "in terms of the context in which they occur, the content of the experience itself, how the experience is remembered later on, and how the experience affects the individual" (p. 130).

Despite the fact that for many years NDEs have been well known in the psychiatric literature as normal, clinical practice has not caught up with the literature. NDEs are still readily dismissed, trivialized, or pathologized by clinicians (Holden, Kinsey, \& Moore, 2014). Particularly when an NDEr states one's experiences honestly and accurately and states that the experiences were taken as real, a clinician can readily misdiagnose the condition as mental illness requiring treatment. Cases of misdiagnosis as mental illness are apparently still very common for veterans who report NDEs. In his article, David Hufford (2014) concluded, referring to extraordinary spiritual experiences (ESEs), which include NDEs, that "the conventional modern attitude toward ESEs is rooted in a pathology model based on cultural prejudice rather than empirical science. The resulting modern dismissal of ESEs as cultural products devoid of rational content is scientifically unfounded and unethical" (p. 153).

\section{Potential Harm}

After an NDE, NDErs are typically certain of what they experienced, because the experiences were intense, vivid, and hyperreal. NDErs know their experiences were real because they were there; they were directly, actively involved in the events and had a direct experience of their reality. NDErs emphatically disagree with and dispute the hypotheses proposed by physicalist skeptics that their experiences were imaginations or lucky guesses, were fabricated from subconsciously perceived impressions, were confabulated with information from other sources, or resulted from their unconscious need to be reassured in the face of death. 
Fischer and Mitchell-Yellin held that NDEs can be deeply meaningful experiences. In their view, NDEs are real experiences that inspire awe and wonder, but they are not accurate experiences: They do not correspond to physical reality. For Fischer and Mitchell-Yellin, NDEs can best be explained in terms of one's brain chemistry and psychology, as deeply meaningful experiences that nonetheless are illusions or hallucinations (p. 169).

Unfortunately, the term "hallucination" nearly universally equates to mental pathology and psychosis, both among the general public and among most mental health clinicians. No qualification of the term, such as "nonclinical hallucination," can nullify this association. NDEs are normal, nonpathological experiences that have profound meaning for and transformative effect on the NDEr. The impact of using "hallucination" to describe NDEs can be very harmful, especially to NDErs who are emotionally vulnerable, confused, or insecure, or who have a weaker sense of self-confidence or self-worth. Regina Hoffman (1995b) described one woman's experience of disclosing her NDE and the resulting dismissive and pathologizing reactions from professionals:

One woman's NDE occurred within a suicide attempt. When she told the psychiatrist what she witnessed from a point outside her body, she recalled the psychiatrist's response: "You're just hallucinating. . . . If I hear stuff like that from you again, then I'm going to have to put you in [the mental ward of local hospital] and lock you up." Despite her continued insistence of the experience's reality coupled with detailed descriptions of resuscitation efforts, the woman found that the psychiatrist "just wouldn't listen." Referred to a social worker shortly afterwards, she decided to try once again to describe the NDE. The social worker called the experience a hallucination and added, "You should not uh, tell people this, because, a, it's not going to help you because that just really did not happen." Soon afterwards she broke off her association with the psychologist because "nobody would listen to me." When I asked why it was so important to have that part of the ordeal discussed, this woman asserted that the NDE "changed me so much" and she wanted that wonderful part of a difficult ordeal to be acknowledged. She interpreted the negative responses to mean that there was something "to be ashamed of" but she wanted people to know that "something good came out of it." More than ten years passed before this person shared descriptions of her NDE openly with a trusted friend who was herself struggling with her child's death. Even then, she proceeded slowly and cautiously, alluding to her NDE on a number of occasions while refusing to elaborate how she knew so much about what awaits after death. (p. 38) 
Although the events of this account occurred several decades ago, this scenario is very common still today, particularly in the U.S. military (Moore, 2017). In a recent study of 88 NDErs, Janice Holden, Lee Kinsey and Travis Moore (2014) found that 19\% of NDErs reported negative responses from all types of healthcare providers, with no significant difference between professional groups and no significant difference by the year of the NDE.

An NDEr is very vulnerable to disconfirming responses, particularly from people in authority-medical personnel, clergy, adults to children, teachers to students, and anyone with purported authoritative knowledge. Experiencing a disconfirming disclosure, especially shortly after the NDE, can readily begin a pattern of nondisclosure that can persist for decades, even a lifetime, with concomitant negative psychological effects, including blocking any future attempts at seeking help. In a study of the disclosure needs of 50 NDErs, Hoffman (1995a) wrote:

A rejection at this [initial] stage can be a devastating experience, sending individuals into communicative isolation for decades afterwards. The experiencers who met with me reported that if there's a choice between what to believe-the truth of the experience or the words of an authority - the experience wins. (p. 249)

Fischer and Mitchell-Yellin may have felt justified in calling NDEs "hallucinations," but if they are sincere about their deep respect for NDErs (p. viii), they should in future writing find terminology that avoids implicitly pathologizing the experience yet maintains their physicalist stance.

\section{Confirmation Bias Cuts Both Ways}

Fischer and Mitchell-Yellin devoted their entire chapter 12 to the syndrome of "confirmation bias," that one tends to believe what one wants to believe. In their view, this idea addresses the reason why people embrace supernatural interpretations of NDEs - the beautiful heavenly realms, being reunited with one's deceased loved ones, the assurance of afterlife, and so on-and eschew other interpretations that may be more accurate or realistic, such as the physicalist interpretation. They explained:

When we exhibit confirmation bias, we fail to consider all relevant hypotheses or explanations. We tenaciously cling to our existing beliefs. We seek out information that accords with those beliefs, and we avoid 
information that is in conflict with them. We fit data to a theory that we are predisposed to like by noticing the confirming hits but not the misses. Confirmation bias is, at bottom, a syndrome of tendencies that protects our already existing beliefs. (pp. 149-150)

The main example of confirmation bias the authors gave is Alexander's second book (2014), The Map of Heaven, which they characterized as "one long exercise in confirmation bias":

Alexander's aim is to specify various reasons why his reader will want to confirm that heaven is for real . . . by giving his readers reason to seek and interpret evidence in a way that will confirm this proposition. He does not examine arguments against supernaturalism and offer reasons for why the view holds up in the face of them. Rather, he marshals only evidence in favor of the view he holds to be true and doubles down with appeals to the benefits of maintaining belief in it. (p. 152)

It is ironic that the authors focused on Alexander's appeal to readers who will succumb to their confirmation bias toward the supernaturalist interpretation of NDEs to manage their fear of death, a bias that "can lead us to ignore what is right in front of our eyes" (p. 155). This is ironic because Fischer and Mitchell-Yellin themselves succumbed to their own confirmation bias about NDErs when they considered the critical article in Esquire magazine by Luke Dittrich (2013) to be an accurate, reliable analysis of Alexander's NDE and his character.

Dittrich's article about Alexander appeared in July 2013 and was immediately criticized by a number of sources on the Internet for being distorted and grossly misleading in every respect about Alexander's NDE (for example, Mays, 2013). In particular, Dittrich misrepresented the statements of the Emergency Room physician who admitted Alexander to the hospital regarding Alexander's level of consciousness. Within days of the article's appearance, the doctor issued a statement to the press that Dittrich had taken her statements out of context, had misrepresented them, and did not accurately portray Alexander's condition. Other criticisms of the facts of Alexander's account of his NDE were also shown to be erroneous (Mays, 2013; SDND, pp. 256-259; and Mays, 2016).

The commentaries disputing the Esquire article have been available on the Internet since 2013, yet Fischer and Mitchell-Yellin apparently were unaware of them or found them not credible. They apparently failed to "consider all relevant hypotheses or explanations" when they quoted verbatim the account from the Esquire article of the Dalai Lama's judgment of Alexander (pp. 176-178). 
In May 2013, His Holiness the Dalai Lama invited Alexander to speak at a symposium as part of the convocation of the Buddhist Maitripa College. The video of the entire ceremony is available (Dalai Lama, 2013). Alexander spoke briefly about his NDE and how his view of past and future lives and the mind's potential had been transformed by it.

At the 44:25-minute point in the video, His Holiness turned to address Alexander and commented about what he had presented. At 45:50, His Holiness explained that phenomena are categorized into "evident phenomena" that can be studied by direct observation, "hidden phenomena" that can be inferred based on observed phenomena, and then the third category of "extremely hidden phenomena" that can be accessed only through first-person experience or the first-person testimony of someone else. Here Dittrich continued the story:

"For that also, we must investigate," the Dalai Lama says. "Through investigation we must get sure that person is truly reliable." He wags a finger in Alexander's direction. When a man makes extraordinary claims, a "thorough investigation" is required, to ensure "that person reliable, never telling lie," and has "no reason to lie." (p. 178)

At the conclusion of the quotation from Dittrich's account, Fischer and Mitchell-Yellin pronounce their agreement with the Dalai Lama, in effect that Alexander is unreliable and a liar: "But we agree with the Dalai Lama that, especially in a context where extraordinary claims are being made, the responsible thing is to inquire critically" (p. 178).

However, Dittrich had left out a crucial part of the Dalai Lama's remarks - the rest of the central sentence. This material changes the Dalai Lama's meaning completely around. One can review the Dalai Lama's full statement on the video of the event at 47:46 minutes in the recording. His Holiness speaks mostly in English but occasionally reverts to Tibetan and has a translator translate into English:

[DL:] And for that also you see, we must investigate. Through investigation we must get sure that person is truly reliable and his experience is something not just illusion of these things. Through then thorough investigation, that person is reliable, never telling lie-and in this particular case, this is no reason to tell lie. Therefore, [Translator:] so then, one can take the testimony to be credible. (Dalai Lama, 2013, 47:46-48:21, emphasis added)

One can see the clever way Dittrich manipulated the meaning of the Dalai Lama's statement to be the exact opposite of His Holiness's actual meaning. Fischer and Mitchell-Yellin have a responsibility in 
repeating an erroneous report about someone's character. Out of their own confirmation bias, they failed to conduct a thorough investigation of the accuracy of Dittrich's article. They failed to consider that it does not even make sense that His Holiness would invite a person to speak at the convocation of one of his colleges, then turn around and proclaim the man unreliable and a liar. Instead, they characterized the Dalai Lama's statement, as Dittrich erroneously reported it, to be "insightful advice from the Dalai Lama" (p. 176).

By uncritically accepting Dittrich's distorted account of Eben Alexander, Fischer and Mitchell-Yellin have amplified Dittrich's errors by giving them the unqualified endorsement of a distinguished professor of philosophy, thereby further unjustly undermining Alexander's good reputation.

\section{Physical or Non-Physical Causation?}

Fischer and Mitchell-Yellin argued that NDE theorists such as Pim van Lommel (2010; 2013) and Alexander (2012) implicitly assumed that a "single explanation" is required to explain NDEs, that "an adequate explanation must invoke only one explanatory factor (perhaps against a background of 'given' conditions)" (p. 78). The problem with "single explanations" is that NDEs are complicated, encompassing various elements-OBEs, life reviews, heavenly realms, etc.- that manifest under diverse circumstances-cardiac arrest, surgery, drownings, etc.- - among diverse individuals. Not all NDEs and not all NDErs are alike in every respect (p. 81). It is entirely possible that multiple factors are involved in NDEs and that these factors give rise to the variety of NDE elements under the various circumstances in which NDEs are reported. We agree in principle with the idea that multifactor explanations are possible for NDEs, but as we showed in the first section of this article, the multi-factor physicalist explanation must rely on so many ad hoc hypotheses that it becomes untenable and improbable.

\section{A Common Proximate Cause for NDEs}

In an earlier paper (Mays \& Mays, 2015), we argued that the evidence from NDEs shows that a "single explanation" of NDEs is actually supported by the data. In addition to the Charland-Verville et al. (2014) finding of no significant difference in either the intensity or content of the NDEs between the "NDE-like" and "real NDE" groups, a further 
study by Charlotte Martial et al. (2016) of the post-NDE changes in personal attitudes, beliefs, and values for individuals reporting a "real NDE" versus "NDE-like experience" showed no substantive difference between the two groups.

These results suggest two things: (a) NDEs occurring at either end of the closeness-to-death spectrum cannot be distinguished: They are the same experience with the same elements, intensity, and aftereffects; and (b) NDEs occur completely independent of NDErs' specific antecedent physiological or psychological conditions and, in some cases, appear to occur spontaneously, that is, with no apparent antecedent condition. Thus, NDEs appear to be a characteristic altered state of consciousness that may be facilitated or triggered by many different types of antecedent conditions or may have no apparent facilitating condition or event. In our 2015 paper, we stated:

The commonality of intensity and content in NDEs-feeling separated from the body, seeing or feeling surrounded by a brilliant light, entering an unearthly world, and so on - under a wide range of conditions suggests that a common state of consciousness occurs during NDEs. The common state of consciousness suggests that there is a common proximate or immediate cause of the experience. There may be any number of antecedent conditions that lead to or trigger a common precipitating cause-a common mechanism - that results in the NDE. An antecedent condition may occur-for example, a cardiac arrest—but if the proximate cause is absent, no NDE occurs, as happens for more than $80 \%$ of cardiac arrest survivors. Conversely, the proximate cause may occur in the absence of a known antecedent condition, resulting in an NDE, as is the case with people who are not near death but who have experiences indistinguishable in content and intensity from experiences that occur in near-death circumstances.

The proximate cause could be a physiological condition that occurs in both near-death and not-near-death circumstances, or it could be some non-physical process. In either case, the explanation based on it would need to account for NDEs occurring in a variety of conditions, including ordinary conditions, [such as] sleep, meditation, or glancing at a sunrise, and would thus satisfy the requirement that it explain all NDEs. It also should account for how, under seemingly identical antecedent conditions - such as two people in cardiac arrest, two people meditating, or even the same person in cardiac arrest or meditating on two different occasions - an NDE does occur in one case and not the other. Furthermore, the explanation should account more broadly for all aspects of all NDEs. (Mays \& Mays, 2015, pp. 130-131, emphasis original) 


\section{A Possible Physiological Proximate Cause for NDEs}

In Mays and Mays (2015), we considered a possible proximate cause with a physiological origin that was proposed by Enrico Facco and Christian Agrillo (2012). They proposed that NDEs may be caused by a physiological agent that triggers a common brain circuit in a particular brain region, such as the temporal lobe or right angular gyrus, or by an agent that works like a psychotropic drug by affecting particular neural receptors, or by some combination of these mechanisms. The agent can be activated in life-threatening situations, in psychiatric and neurological disorders, and in nonclinical situations, such as hypnosis, meditation, role transitions and deep existential crises, to induce the altered state of consciousness of an NDE. Although Facco and Agrillo did not elaborate any further how specific features of NDEs could arise from their model, further elaborations are possible.

Even if this common physiological cause could be identified, this theory would still need to account for all aspects of all NDEs in order to be a "complete explanation" (p. 78). Unfortunately, as we showed in the first section of this article and in Mays and Mays (2015), a single factor physicalist explanation would still need to rely on quite a number of ad hoc hypotheses to explain the unusual aspects of NDEs. For example, an unusual physiological sensory ability would be needed to explain how NDErs accurately report events at far distances or accurately describe unusual objects observed out of the physical line of sight of anyone present. Such abilities are so speculative and unusual as to be extremely dubious.

\section{A Possible Nonphysical Proximate Cause for NDEs}

In earlier papers, we proposed another possible proximate cause of NDEs that is independent of physiology and psychology, based on the view that the human being consists of a nonmaterial "mind" that is spatially coextensive and usually intimately integrated with the physical body (Mays \& Mays, 2008; 2011; 2015). J. Kenneth Arnette's (1992, 1995, 1999) theory of essence is another exposition of this idea. The mind or "essence" of a person is an objective, autonomous entity, a "field of consciousness," that interacts energetically with the brain's 
neural electrical activity to mediate all cognitive faculties. The mind is the seat of consciousness of the person, the subject in which phenomenal experience occurs. Ordinarily, electrical interaction between the brain and the mind is required for phenomenal experience and consciousness.

In this view, a person's "mind entity" can, under various conditions, separate from and operate independent of the physical body. There are thus two states of consciousness: an "in-body" state, whereby the mind is united with the brain and body and is dependent on the brain for normal cognitive functions (perception, thought, volition, memory, etc.), and an "out-of-body" state whereby the mind is separated from the brain and body and can function completely independent of them. In the separated state, there is no brain interaction; thus, visual, auditory, and other sensations occur directly in the mind without the physical sensory apparatus of the brain.

A major objection Fischer and Mitchell-Yellin have to a nonphysical mind is the need to explain how the nonphysical mind could interact with the physical in a causal way (pp. 95-96). They believe it is a "tall order" to explain several things. First, how do the relevant nonphysical factors explain the phenomena of NDEs? Second, how do the nonphysical factors interact with one's physical body in "normal" circumstances, that is, how could an NDEr see her physical body during cardiac arrest and also have normal visual experiences involving causal interactions between the nonphysical and physical realms? Third, how can an NDEr recall and describe her NDE once her physical body returns to good working order, given that her experience of the NDE occurred without the physical brain?

These questions are actually fairly easy to address from the mindentity theory. Following is a summary of the more detailed elaboration in Mays and Mays (2015). First, the nonmaterial mind entity can separate from the physical body in both life-threatening and non-lifethreatening circumstances, as described earlier. The separated mind entity is the "essence" of the person in which all cognitive functions operate. The mind entity can interact with physical phenomena, such as light and sound, to support perceptions of the physical surroundings. The NDEr's perceptions are heightened and veridical because they are direct perceptions, not mediated by the physical senses. In addition, the NDEr's mind can sometimes perceive the thoughts others in the vicinity are having. The NDEr's thought processes are more lucid and memories of the experience form directly in the mind, with- 
out the mediation of the brain. The mind entity is not constrained by gravity or solid objects, and the mind can travel readily, simply by thinking of the place or person one wants to see. In passing through solid objects, many NDErs report a slight sensation of resistance or a slight increase in density (Mays \& Mays, 2008, pp. 21, 33). These sensations indicate another subtle interaction with physical matter and forces. The NDEr's mind entity can go through a transition, for example via a tunnel, to transcendent realms and can encounter deceased persons or spiritual beings. The accounts of these realms and beings are surprisingly consistent among many NDErs, but their exact form in a given NDE seems to be influenced by the NDEr's expectations or background. Finally, the NDEr returns to the physical body and reunites with it, again experiencing the physical realm through the physical body and senses.

Second, the nonmaterial mind entity interacts with the physical body in "normal" circumstances, through causal interactions with the brain and bodily nerves. There is significant evidence of physical interactions of the mind entity in NDEs beyond what we have mentioned here (Mays \& Mays, 2008; 2011). Further, we propose that the primary interface between the mind and brain occurs in the apical dendrites of the pyramidal cells in the neocortex (Mays \& Mays, 2011). Because the mind entity is intimately united with the brain in ordinary consciousness, there is a very strong correlation between neural activity and phenomenal experience. In the "in-body" state, the mind is dependent on the brain for normal cognitive functions-perception, thought, volition, memory, etc.- - through the electrical activity of the brain neurons.

Third, the NDEr can recall and describe her NDE once her physical body returns to good working order because all memories are formed in the mind, not in the brain. Memories of ordinary events experienced in the physical body are formed in the mind via the hippocampus, but memories of the events of an NDE are formed directly in the mind as semantic knowledge. Thus, the memories of the NDE are vivid and indelible compared even to ordinary memories of real events (Mays \& Mays, 2016).

In addition to explaining NDEs, the mind-entity theory explains some of the major enigmas of consciousness and the brain, such as the "hard problem" of consciousness (Chalmers, 2010), that is, how electrical activity in brain neurons turns into subjective phenomenal experience. In this theory, phenomenal experience occurs from the in- 
teraction of cortical electrical activity with the mind entity, which is the seat of consciousness. The interaction gives rise to the phenomenal experience in the mind.

Another enigma is the "binding problem" (Bayne \& Chalmers, 2003), that is, how the qualities of phenomenal experience seem to come together in a complete, seamless unity of experience from different, widely separated regions of the brain. In this theory, phenomenal experience appears unified because the mind as the seat of consciousness is unitary. The disparate elements of phenomenal experience are unified within the mind, resulting in the seamless unity of consciousness.

We believe that the mind-entity theory is a sufficiently robust "single explanation" to address all aspects of all NDEs, as well as provide the basis for understanding the operation of ordinary consciousness in the physical body. We also believe that the patterns of neural activations reported in cognitive neurophysiological studies can be interpreted in light of the nonmaterial mind entity's interface with the brain to provide a full explanation of the neural correlates of consciousness and cognitive function (Mays \& Mays, 2017).

\section{Hope for a Physical Theory or Merely Promissory Materialism?}

Throughout their book, Fischer and Mitchell-Yellin appealed to the ultimate success of scientific progress to provide physical explanations that, in the future, will fully explain NDEs. This argument seems to be their strongest argument for physicalism. For example, see the quote from the book (p. 66) in the first section of this article and these quotes:

We should not dismiss, out of hand, the possibility that future progress may allow us to provide scientific explanations of things we cannot currently make sense of within the reigning scientific paradigm. (p. 28)

Given that the relevant sciences are in their infancy and that the physical sciences provide us with an ever-expanding body of knowledge, it would seem reasonable to assume that our current state of knowledge is not representative of physicalism's prospects. (p. 101)

Arguments of this form are what Karl Popper called "promissory materialism" (Popper \& Eccles, 1977, pp. 96-98). For Popper, promissory materialism is a very weak argument and is actually meaning- 
less because it cannot be used before the fact to refute any nonphysical theory.

If the evidence for a complete physical explanation of NDEs finally develops through neuroscience and other physical sciences, that evidence can be used to refute the nonphysical theory. What is more likely to happen, however, is that neuroscience will correct and refine the nonphysical theory-if the theory has explanatory power-through the normal process of scientific inquiry (Kuhn, 1970, Section XII). For example, neuroscience could refine the nonphysical theory by providing details and empirical evidence of how the nonmaterial mind interfaces with the brain. The result will be an expansion of physicalist theory to include what is now considered supernatural, becoming an extended naturalist theory, one admitting of transmaterial realities.

\section{Conclusions}

In their book, John Fischer and Benjamin Mitchell-Yellin presented well-crafted arguments for purely physicalist explanations of NDEs and against supernatural explanations. Supernatural explanations make reference to transcendent realities such as heavenly realms, spiritual beings, deceased human beings, an afterlife, and a nonphysical soul or mind.

We found two major weaknesses in Fischer and Mitchell-Yellin's arguments. To summarize:

- The number of $a d$ hoc hypotheses necessary to explain aspects of NDEs that do not fit the physicalist paradigm rendered even a theory as firmly established as physicalism untenable.

- The invocation of "promissory materialism" to explain those aspects is extremely weak; a non-physical theory cannot logically be refuted before the fact but can be refuted only through actual evidence resulting from ordinary scientific inquiry.

In addition, we objected to other aspects of Fischer and MitchellYellin's treatment of NDEs:

- Use of the term "hallucinations" to apply to perceptions during an NDE is both invalid and undesirable, because (a) both NDErs themselves have insisted and multiple researchers have found that the phenomenology of NDE and hallucinatory percepts is quite different; (b) the pre/trans fallacy-conflating prerational and trans-rational states-ignores research findings of the consistency, memorability, and veridicality of the latter but not the former; and (c) the term "hallucination" conjures 
associations with psychological pathology and perpetuates the clinical error of diagnosing NDErs with psychological disorder-frequently resulting in harmful outcomes-despite abundant evidence that NDEs are unrelated to psychopathology.

- Ironically, Fischer and Mitchell-Yellin placed particular emphasis on "confirmation bias" without realizing their own, illustrated particularly by their perpetuation of distortions and misinformation in Dittrich's (2013) Esquire article about Alexander's NDE and his character.

In response to Fischer and Mitchell-Yellin's argument against requiring a "single explanation" of NDEs, we asserted:

- that the evidence from recent studies of NDEs shows that NDEs are the same in the content and intensity regardless of the antecedent conditions, strongly suggesting a common proximate cause for all NDEs, either physical or nonphysical.

- that a nonphysical theory, the "mind-entity theory," in which the nonmaterial mind separates from the physical body in an NDE, is a likely candidate theory of NDEs with good explanatory power. This theory satisfies Fischer and Mitchell-Yellin's "tall order" criteria for "an adequate and complete supernatural explanation of NDEs" (p. 96), and explains a number of enigmas of consciousness, such as the "hard problem." Although openness to considering a nonphysical theory will require a paradigm shift among most current scientists, we expect that those who make the shift will test, verify, correct, and refine this or a similar nonphysical theory - if the theory has explanatory powerthrough the normal process of scientific inquiry. The result will be an expansion of physicalist theory to include what is now considered supernatural, becoming an extended, transmaterial naturalist theory.

\section{References}

Alexander, E. (2012). Proof of heaven: A neurosurgeon's journey into the afterlife. New York, NY: Simon \& Schuster.

Alexander, E. (with Tompkins, P.). (2014). The map of heaven: How science, religion, and ordinary people are proving the afterlife. New York, NY: Simon \& Schuster.

American Psychiatric Association. (1994). Diagnostic and statistical manual of mental disorders (4th ed.). Washington, DC: Author.

Arnette, J. K. (1992). On the mind/body problem: The theory of essence. Journal of Near-Death Studies, 11(1), 5-18. doi:10.17514/JNDS-1992-11-1-p5-18.

Arnette, J. K. (1995). The theory of essence. II. An electromagnetic-quantum mechanical model of interactionism. Journal of Near-Death Studies, 14(2), 77-99. doi:10.17514/JNDS-1995-14-2-p77-99.

Arnette, J. K. (1999). The theory of essence. III: Neuroanatomical and neuro- 
physiological aspects of interactionism. Journal of Near-Death Studies, 18(2), 73-101. doi:10.17514/JNDS-1999-18-2-p73-101.

Bayne, T., \& Chalmers, D. J. (2003). What is the unity of consciousness? InA. Cleeremans (Ed.), The unity of consciousness: Binding, integration and dissociation (pp. 23-58). Oxford, UK: Oxford University Press. doi:10.1093/acprof:oso/ 9780198508571.003.0002

Burpo, T. (with Vincent, L.). (2010). Heaven is for real: A little boy's astounding story of his trip to heaven and back. Nashville, TN: Thomas Nelson.

Chalmers, D. J. (2010). The character of consciousness. New York, NY: Oxford University Press. doi:10.1093/acprof:oso/9780195311105.001.0001.

Charland-Verville, V., Jourdan, J.-P., Thonnard, M., Ledoux, D., Donneau, A.-F., Quertemont, E., \& Laureys, S. (2014). Near-death experiences in non-lifethreatening events and coma of different etiologies. Frontiers in Human Neuroscience, 8, 203. doi:10.3389/fnhum.2014.00203.

Dalai Lama. (2013, May 10). Life and after life. Retrieved from https://www .youtube.com/v/-inGigVypl4.

Dittrich, L. (2013, August). The prophet: An investigation into Eben Alexander, author of the blockbuster Proof of Heaven. Esquire, 160(1), 88-95, 125-127. Retrieved from http://www.esquire.com/entertainment/interviews/a23248/theprophet/.

Facco, E., \& Agrillo, C. (2012). Near-death-like experiences without lifethreatening conditions or brain disorders: A hypothesis from a case report. Frontiers in Psychology, 3, 490. doi:10.3389/fpsyg.2012.00490.

Fischer, J. M., \& Mitchell-Yellin, B. (2016). Near-death experiences: Understanding visions of the afterlife. New York, NY: Oxford University Press.

Greyson, B. (2014). Differentiating spiritual and psychotic experiences: Sometimes a cigar is just a cigar. Journal of Near-Death Studies, 32(3), 123-136. doi:10.17514/JNDS-2014-32-3-p123-136.

Hoffman, R. M. (1995a). Disclosure needs and motives after a near-death experience. Journal of Near-Death Studies, 13(4), 237-266. doi:10.17514/JNDS1995-13-4-p237-266.

Hoffman, R. M. (1995b). Disclosure habits after near-death experiences: Influences, obstacles, and listener selection. Journal of Near-Death Studies, 14(1), 29-48. doi:10.17514/JNDS-1995-14-1-p29-48.

Holden, J. M. (2009). Veridical perception in near-death experiences. In J. M. Holden, B. Greyson, \& D. James (Eds.), The handbook of near-death experiences: Thirty years of investigation (pp. 185-212). Santa Barbara, CA: Praeger/ ABC-CLIO.

Holden, J. M., Kinsey, L., \& Moore, T. R. (2014). Disclosing near-death experiences to professional healthcare providers and nonprofessionals. Spirituality in Clinical Practice, 1(4), 278-287. doi:10.1037/scp0000039.

Hufford, D. (2014). The healing power of extraordinary spiritual experiences. Journal of Near-Death Studies, 32(3), 137-156. doi:10.17514/JNDS-2014-32-3p137-156.

Johnson, C. V., \& Friedman, H. L. (2008). Enlightened or delusional? Differentiating religious, spiritual, and transpersonal experiences from psychopathology. Journal of Humanistic Psychology, 48(4), 505-527. doi:10.1177/ 0022167808314174. 
Kolp, E., Young, M. S., Friedman, H., Krupitsky, E., Jansen, K., \& O’Connor, L. (2007). Ketamine-enhanced psychotherapy: preliminary clinical observations on its effects in treating death anxiety. International Journal of Transpersonal Studies, 26, 1-17.

Kuhn, T. S. (1970). The structure of scientific revolutions (2nd enl. ed.). Chicago, IL: University of Chicago Press.

Liester, M. B. (2013). Near-death experiences and ayahuasca-induced experiences-two unique pathways to a phenomenologically similar state of consciousness. Journal of Transpersonal Psychology, 45(1), 24-48.

Martial, C. (2016). Characteristics of near-death experience memories and personal changes following near-death experiences. Paper presented at the 2016 annual conference of the International Association for Near-Death Studies (IANDS), Orlando, FL. Retrieved from http://conference.iands.org/2016speakers/\#martial

Martial, C., Charland-Verville, V., Cassol, H., Didone, V., Van Der Linden, M., \& Laureys, S. (2017). Intensity and memory characteristics of near-death experiences. Consciousness and Cognition. Advance online publication. doi:0.1016/ j.concog.2017.06.018.

Mays, R. G. (2013). Esquire article on Eben Alexander distorts the facts. Retrieved from http://iands.org/esquire.

Mays, R. G. (2016). Eben Alexander's near-death experience: How an Esquire article distorted the facts. Journal of Near-Death Studies, 35(2), 65-93. doi: 10.17514/JNDS-2016-35-2-p65-93.

Mays, R. G., \& Mays, S. B. (2008). The phenomenology of the self-conscious mind. Journal of Near-Death Studies, 27(1), 5-45. doi:10.17514/JNDS-200827-1-p5-45.

Mays, R. G., \& Mays, S. B. (2011). A theory of mind and brain that solves the 'hard problem' of consciousness. Paper presented at the 2011 annual conference of the International Association for Near-Death Studies (IANDS), Durham, NC. Retrieved from http://selfconsciousmind.com/papers.html\#theory-article.

Mays, R. G., \& Mays, S. B. (2015). Explaining near-death experiences: Physical or non-physical causation? Journal of Near-Death Studies, 33(3), 125-149. doi:10.17514/JNDS-2015-33-3-p125-149.

Mays, R. G., \& Mays, S. B. (2016). Unraveling the mystery of memory: EEG evidence from near-death experiencers. Paper presented at the 2016 annual conference of the International Association for Near-Death Studies (IANDS), Orlando, FL. Retrieved from https://www.youtube.com/watch?v=1GlKv_mfiqg.

Mays, R. G., \& Mays, S. B. (2017). Near-death experiences and the neural correlates of consciousness. Paper presented at the 2017 annual conference of the International Association for Near-Death Studies (IANDS), Westminster, CO. Retrieved from https://www.youtube.com/watch?v=nYgiEUXNI9s.

Moore, L. E., \& Greyson, B. (2017). Characteristics of memories for near-death experiences. Consciousness and Cognition, 51, 116-124. doi:10.1016/j.concog .2017.03.003.

Moore, R. (Producer \& Director). (2017). Understanding veterans' near-death experiences [DVD]. Estero, FL: Roberta Moore Productions.

Palmieri, A., Calvo, V., Kleinbub, J. R., Meconi, F., Marangoni, M., Barilaro, P., ... \& Sessa, P. (2014). "Reality" of near-death-experience memories: Evidence 
from a psychodynamic and electrophysiological integrated study. Frontiers in Human Neuroscience, 8(429), 1-16. doi:10.3389/fnhum.2014.00429.

Popper, K. R., \& Eccles, J. C. (1977). The self and its brain: An argument for interactionism. London, UK: Routledge. doi:10.1007/978-3-642-61891-8.

Punzak, D. (2016). Near-Death Experiences: Understanding Visions of the Afterlife, by John Martin Fischer and Benjamin Mitchell-Yellin [Book review]. Journal of Near-Death Studies, 34(4), 224-232. doi:10.17514/JNDS-2016-34-4p224-232.

Ring, K. (1980). Life at death: A scientific investigation of the near-death experience. New York, NY: Coward, McCann and Geoghegan.

Rivas, T., Dirven, A., \& Smit, R. H. (2016). The self does not die: Verified paranormal phenomena from near-death experiences. Durham, NC: International Association for Near-Death Studies.

Sabom, M. B. (1982). Recollections of death: A medical investigation. New York, NY: Harper and Row.

Sacks, O. (2012). Hallucinations. New York, NY: Alfred A. Knopf.

Sartori, P. (2008). The near-death experiences of hospitalized intensive care patients: A five year clinical study. Lewiston, UK: Edwin Mellen Press.

Thonnard, M., Charland-Verville, V., Brédart, S., Dehon, H., Ledoux, D., Laureys, S. \& Vanhaudenhuyse, A. (2013). Characteristics of near-death experiences memories as compared to real and imagined events memories. PLoS ONE, 8(3): e57620. doi:10.1371/journal.pone.0057620.

van Lommel, P. (2010). Consciousness beyond life: The science of the near-death experience. New York, NY: Harper-Collins.

van Lommel, P. (2013). Non-local consciousness: A concept based on scientific research on near-death experiences during cardiac arrest. Journal of Consciousness Studies, 20(1-2), 7-48.

Wilber, K. (2000). Sex, ecology, spirituality: The spirit of evolution. Boston, MA: Shambhala. 